\title{
Socio-Economic Conditions and Challenges of the Modern Living of the Old People in Terms of Contemporary Social Care in Republic of Macedonia
}

\section{PhD Hava Rexhep}

\author{
Ministry of labor and social policy - Ohrid
}

hava_r@live.com

\author{
Ajsha Rexhep \\ MsC Candidate in English language methodology, Lecturer at International University of Struga \\ a.salkoska@eust.edu.mk
}

\section{Doi:10.5901/ajis.2015.v4n1s2p89}

\begin{abstract}
For many people the pensioning is a new condition as well as new challenge fulfilled with many news and uncertainty. The fact that the work lifetime is finished, involves him in a totally unknown and new situation, a challenge which leads to cancelling of all that have fulfilled their lives till then. The person at that age must face up with the truth that his work abilities are getting weaker and it is the right time to retire and leave the workplace to the younger generation. Oftentimes the challenges in the old people life are with negative connotation, followed with feeling of confusion, consternation, inferiority, decreased selfconfidence and high sentimentality in relations with the other people. Also, the conditions of pensioning are followed with new problems which must be overcome. The main aim of this research paper is to investigate the conditions and challenges in the modern living of the old people in terms of contemporary social care in Republic of Macedonia. In the investigation of the social care of the old people, we treated the organized and spontaneous forms, acts and activities which reflect the quality of living of the old people. In the investigation are included 600 participants above 60 years old with stratified example in appropriate relation by age and gender, place of living (Skopje, Kumanovo, Kicevo and Strumica) and ethnicity, and at the same time the example is designed based on the institutions where the investigation is completed. The findings on the status and challenges of the aging are based on the strive for the realization of progressive approaches, legislation, programs and strategies to improve the lives of the old people. The main aim of this research is gaining knowledge and challenges in contemporary life of the old people, especially in terms of social care to create conditions, guidelines and bases for an organized approach.
\end{abstract}

\section{Introduction}

The old people represent a big and according to many things special category of the population. For many people the period of aging begins with the pensioning. It is a significant change in their lives, because it comes rapidly to a stop of the everyday life and work which has lasted for years and more for decades. During this period the life and work of the old people had a particular order of happening, they get up in a particular time, go to work at a particular time and they organized regular activities in the environment. For all that time they communicated with known group of people, related to the workplace. In that environment the person had built own position, reputation and relations with the colleagues with whom he become related with on some way. He shares the common problems with them; he shares the good and the bad, built common interests, conscious that he is an important part of the working environment, indeed he contributes with his work not only for his personal but also for the social good. With the pensioning, respectively the third age starting, the person must quit many things which had fulfill his everyday life, he must separate forever from that environment, leave it forever.

For many people the pensioning is a new condition as well as new challenge fulfilled with many news and uncertainty. The fact that the work lifetime is finished, involves him in a totally unknown and new situation, a challenge which leads to cancelling of all that have fulfilled their lives till then.

The person at that age must face up with the truth that his work abilities are getting weaker and it is the right time to retire and leave the workplace to the younger generation. Oftentimes the challenges in the old people life are with negative connotation, followed with feeling of confusion, consternation, inferiority, decreased self-confidence and high sentimentality in relations with the other people. 
Also, the conditions of pensioning are followed with new problems which must be overcome. Those problems come from different recourses, firstly from the psychological adaptation in the new role in the family as well as in the society, the need of better dedication to the health problems, the need of knowing appropriate law regulations which regulate his right as a pensioner, the need of introducing the system of social protection of the old people and etc.

In our research paper we decided to investigate the conditions and challenges in the modern living of the old people from an aspect of contemporary social care in Republic of Macedonia. In the investigation of the social care of the old people we treated the organized and spontaneous forms, acts and activities which reflect the quality of living of the old people. In that relation they are dependent of the place of living of the old people, the service accessibility and the institutions for social care and protection (clubs, centers, advisories, nursing and retirement homes), the life education and the information technology, legal regulations and etc.

In the investigation are included 600 participants above 60 years old with stratified example in appropriate relation by age and gender, place of living (Skopje, Kumanovo, Kicevo and Strumica) and ethnicity, and at the same time the example is designed based on the institutions where the investigation is completed as: in the premises of the registry ambulances (280 participants, respectively 47\%), clubs and daily centers (155 participants respectively 26\%), retirement homes (60 participants respectively 10\% of the sample) and nursing homes, state and private (105 participants respectively 18\%). In the research are inquired 600 old people older than 60 from the both genders.

\section{Socio- economic Conditions}

The socio-economic conditions of the old people are very important indicators in this research. From many indicators characteristic for the old people we decided to investigate three of them which are part of three basic components in terms of place of living, the existence and the services. In the frameworks of these criteria are investigated the following indicators: who the old person lives with, cutting the family budget distribution and the services.

The socio-economic conditions are objective indicator of the quality of living of the old people, not only in terms of the current condition, but also there are built the challenges as basic parts of the appropriate forms and content demand.

\subsection{Who the old people live with}

Investigating the condition who the old people live with there are proposed five indicators: alone, with the husband/wife, alone with the children, with the husband/wife and the children and others (brother, sister, nephew). The data of this research are presented in table no. 1. 1 Old people by age and gender and who the old people live with. From the presented data it is clear the biggest percent of the old people, around 35\%, live alone, out of who the males and females are nearly with the same representation in percents. The females from 70-79 years are representing $10 \%$, which shows us that an important percent of the females live alone so we guess that they face up serious problems form different aspects. Also, nearly similar percent of the old people live with the partner or alone with the children (around $23 \%$ and $20 \%$ ). With the partner and children live a small percentage of the old people. These environments are characteristic for the younger age of the old people which emphasizes the fact that the old people of early aging are very helpful in the family by finishing important functions in the family life realization.

The table shows that the highest percent of the old people live in families. This confirms our hypothesis that despite the decreased role in the family the old people still decide to live in the family.

The lowest percent of the old people live in family with close relatives which show that the biggest number (around $60 \%$ ) decides to live in a community despite the individual living. Despite the crisis in the modern family, the family was and always will be basic cell of the social living of the person, due to that of the old people too.

Table no. 1.1: The old people by age and gender and who they live with

\begin{tabular}{|c|c|c|c|c|c|c|}
\hline \multicolumn{7}{|c|}{ Old people by age and gender } \\
\hline \multirow{7}{*}{ 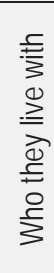 } & & $60-79$ & $70-79$ & over 80 & Total & \multirow{2}{*}{ Total } \\
\hline & & $\mathrm{M} \quad \mathrm{F}$ & $\mathrm{M} \quad \mathrm{F}$ & $M$ & $\mathrm{M}$ & \\
\hline & & $f$ & $f$ & $f$ & $f$ & $f$ \\
\hline & & $\%$ & $\%$ & $\%$ & $\%$ & $\%$ \\
\hline & \multirow{2}{*}{ Alone } & 25 & 40 & 25 & 119 & 209 \\
\hline & & $4,16 \% 5 \%$ & $6,66 \% 9,83 \%$ & $4,16 \% \quad 5 \%$ & $15 \% 19,83 \%$ & $34,83 \%$ \\
\hline & With the partner & $41 \quad 30$ & 10 & 10 & 86 & 136 \\
\hline
\end{tabular}




\begin{tabular}{|c|c|c|c|c|c|}
\hline & $6.83 \% 5 \%$ & $5,83 \% 1,67 \%$ & $1,76 \% 1,67 \%$ & $14,34 \% 8,33 \%$ & $22,69 \%$ \\
\hline \multirow{2}{*}{ Alone with the children } & 26 & 30 & 25 & 50 & 121 \\
\hline & $0,83 \% 4,33 \%$ & $5 \% \quad 3,36 \%$ & $2,5 \% 416 \%$ & $8,33 \% 11,83 \%$ & $20,16 \%$ \\
\hline \multirow{2}{*}{ With the partner and the children } & 30 & 20 & 10 & 60 & 106 \\
\hline & $5 \% \quad 4,16 \%$ & $3,36 \% \quad 1,8 \%$ & $1,66 \% 1,66 \%$ & $10 \% \quad 7,66 \%$ & $17,66 \%$ \\
\hline \multirow{2}{*}{$\begin{array}{l}\text { With,others,brother, } \\
\text { sister,nephew }\end{array}$} & 10 & 3 & 0 & 13 & 28 \\
\hline & $1,66 \% 0,83 \%$ & $0,5 \% 1,33 \%$ & $0 \% \quad 0,33 \%$ & $2,16 \% 2,5 \%$ & $4,66 \%$ \\
\hline \multirow{4}{*}{ Total } & $111 \quad 116$ & 128 & 77 & 299 & 600 \\
\hline & $18,5 \% 19 \%$ & $21,3 \% 18 \%$ & $10 \% 12,8 \%$ & $49,8 \% 50 \%$ & $100 \%$ \\
\hline & 227 & 236 & 137 & 600 & \\
\hline & $37,83 \%$ & $39,34 \%$ & $22,83 \%$ & $100 \%$ & \\
\hline
\end{tabular}

The data visible in Table 1. 1 Old people by age and gender and who the old people live with despite the table presentation are open to more detailed statistic analysis in order to objectively confirm the theory of the hypothesis. Statistic indicators of the sample

\begin{tabular}{|c|c|c|c|}
\hline Symbols & $x^{2}$ & C & N \\
\hline Values & 107,607 & 0,389 & 600 \\
\hline
\end{tabular}

Statistic indicators of the theoretical values which helped the examination

\begin{tabular}{|c|c|c|c|}
\hline Symbols & Df & $\mathrm{P} \%$ & theoretical ${ }^{2}$ \\
\hline \multirow{2}{*}{ Theoretical values } & 8 & 5 & 15,31 \\
\cline { 2 - 4 } & 8 & 1 & 20,09 \\
\hline
\end{tabular}

The dimension of $x^{2}$ and the contingency intensity show that there is an important statistic relation between the old people and the proposed forms of who they live with.

It is an interesting finding that came up from our research that the biggest number of the old people during the period of preparation for the aging were thinking of living alone or with the partner, but when they are facing up with the reality which comes with the age they accept that living alone or the loneliness is the most likely form of quality living. Regardless the quality of living of the old people in the family, they are easily adapting to this form of living.

\subsection{Cutting and distribution of the total incomes}

While distributing the total incomes the old people own very often they are obliged to stretch the total income from $1^{\text {st }}$ to $1^{\text {st }}$, at the same time giving efforts to do that. They, with the relatively modest pensions, are faced up every day with the increased life costs and almost all of them are obliged to be very careful in total incomes distributing, especially in terms of giving up from the basic life needs.

Regarding the previous mentioned we consider as very important to present a table for cutting during the total income distribution respectively the pension they have. Also we considered as very important to emphasized that the old people who live in families (and they are happy about this), often use their pension to pay the overheads, and very often they are not allowed to manage alone the rest of the sum because their children do that instead. Related to this we considered as very important to investigate what are the things they skimp on respectively they give up when spending money for existence. In this direction we considered as useful top emphasize, once again, that cutting the total income distribution does not mean no paying the overheads and the other expenses, but firstly to concentrate on saving, respectively separating minimal finances for satisfying the basic life needs. The results of the research are presented in Table no. 1.7 the old people by age and gender and what are the things the cut when distributing the total incomes.

In the table, the attitudes of the old people are divided in three adult categories, because we considered that the adultness has a huge influence on the capabilities of the old people in managing their own total incomes. Also we considered as very important to analyze and investigate the basic indicators when distributing the total incomes and we decided for the overheads, food, medicines, clothes and furniture, culture and communication.

Table no. 1. 2: The old people by age and gender and what are the things they cut when distributing the total incomes. 


\begin{tabular}{|c|c|c|c|c|c|c|}
\hline \multicolumn{7}{|c|}{ Old people by age and gender } \\
\hline \multirow{4}{*}{ 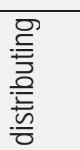 } & & $60-69$ & $70-79$ & over 80 & Total & \multirow{2}{*}{ Total } \\
\hline & & $M$ & $M$ & $M$ & $M$ & \\
\hline & & $f$ & $f$ & 1 & $f$ & $f$ \\
\hline & & $\%$ & $\%$ & $\%$ & $\%$ & $\%$ \\
\hline \multirow{6}{*}{ 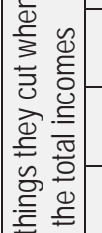 } & \multirow[t]{2}{*}{ Overheads } & 73 & 42 & 54 & 140 & 237 \\
\hline & & $8,88 \% 14,74 \%$ & $8,48 \% \quad 0,80 \%$ & $10,90 \% \quad 4,04 \%$ & $28,28 \% 19,59 \%$ & $47,87 \%$ \\
\hline & \multirow[t]{2}{*}{ Food } & 60 & 52 & 30 & 122 & 262 \\
\hline & & $8,08 \% \quad 12,12 \%$ & $10,50 \% 8,08 \%$ & $6,06 \% \quad 8,08 \%$ & $24,64 \% 28,28 \%$ & $52,92 \%$ \\
\hline & \multirow[t]{2}{*}{ Medicines } & 20 & 15 & 80 & 53 & 113 \\
\hline & & $6,06 \% \quad 4,04 \%$ & $4,04 \% 3,03 \%$ & $2,22 \% 16,16 \%$ & $12,12 \% \quad 10,70 \%$ & $22,82 \%$ \\
\hline$\stackrel{\varrho}{\leftrightarrows}$ & \multirow[t]{2}{*}{ Clothes and furniture } & 92 & 100 & 43 & 236 & 459 \\
\hline$\stackrel{\varpi}{\varpi}$ & & $16,16 \% 18,58 \%$ & $20,20 \% 16,16 \%$ & $8,68 \% 12,92 \%$ & $45,05 \% 47,96 \%$ & $92,72 \%$ \\
\hline$\stackrel{\pi}{\pi}$ & \multirow[t]{2}{*}{ Culture and communication } & 95 & 80 & 52 & 160 & 430 \\
\hline$\sum_{3}^{5}$ & & $19,19 \% 9,69 \%$ & $16,16 \% 12,12 \%$ & $19,19 \% 10,50 \%$ & $54,54 \% 32,32 \%$ & $86,86 \%$ \\
\hline
\end{tabular}

By hypothesis that from the spending, often subject of saving, respectively cutting, when distributing the total family incomes, a significant percent of the old people $, 78,87 \%$, declared that they maximally saved in the overheads, example they prepare food two or three times a week, use cheaper electricity, are modest in spending water, and other expenses where possible.

Related to the food a high percent of the old people declared that they save on food, use cheap products, some of them with expanded deadline, and to buy few minutes before the shops are closing because they expect cheaper prices $(52,92 \%)$

The old people also save on medicines despite the fact that their health is at risk respectively they get chronicle illness and it is necessary to get the medicine. Despite the conscious health policy which allows relatively cheap and available medicines for most often illnesses of the old people, however $22,82 \%$ declared that the cut in buying medicines respectively they are not able to buy them. In table no. 1. 2 The old people by age and gender and what are the things they cut when distributing the total incomes, it is very clear that the highest percent of cutting of the total pensioning income is related to the impossibility to buy clothes and furniture, $92,72 \%$, and also for cultural organizations and communication so this percentage is $86,86 \%$. This indicator is relatively high from one side, and because of inability of the third category to participate, but also the indicators from the second category are important.

This percentage is not highly represented relating to the public transport, because it was organized to have it four times a week. The research shows that a big percent of the old people save on the public transport during the days they must pay. In this direction, analyzing the whole data in the table and the diagram, we can conclude that the old people are continuously cutting the total income of the pension, so they save on many necessary and important things that make the life of the old people more secure and fulfilled with pleasure and satisfaction.

\subsection{Services}

The modern way of living decreases the scope of the traditional relation with the old people by the family, against the legal obligations and duties. More and more, the modern living conditions impose the need of including the state in many forms of the social care. Respecting the need of the old people to live in their own home (as long as possible), we considered as important to investigate the types of services which are realized in the old people's homes in terms of their availability and accepting by the users. The data of this need investigation is presented in Table 1. 3 Age and gender of the old people and the types of services. Basic indicators of the services for the old people are: addition to cash compensation for assistance and care of another person, help at home (Red Cross, etc. ), private service engagement, service delivery of food and transportation. The results gained and the answers of the old people are presented in table with numbers and percents, and also in diagram for more clear view of the proposed indicators. In the table we can see that the biggest percent of the old people (100\%), from Skopje use the public transport as a service. In that direction it is very important to emphasize that this step of the country is accepted with a great pleasure by the old people, not only to use the free time, but also to complete some personal everyday needs, duties and etc.

This pleasure the old people express not only in mutual discussions, but can be seen from their smiling faces when riding the bus. In terms of other services we can notice that financial compensation for care of another person with 22. $22 \%$ and private service engagement with $16.16 \%$ in a relatively small percentage are represented in the lives of the old 
people.

However it is important to emphasize that despite the large need of the old people for help at home is very poor realized mostly by short projects of the civic associations. A possible reason for the difficulty of the implementation of this service lies in the poor information and preparation of the old people to accept this form, because basically they are often suspicious and reluctant to accept a stranger into your home, even for their direct benefit. A serious problem of the old people in the second, and even more in the third age group is the need for grocery shopping and preparation of daily meals.

Table no. 1. 3. Age and gender of the old people and types of services

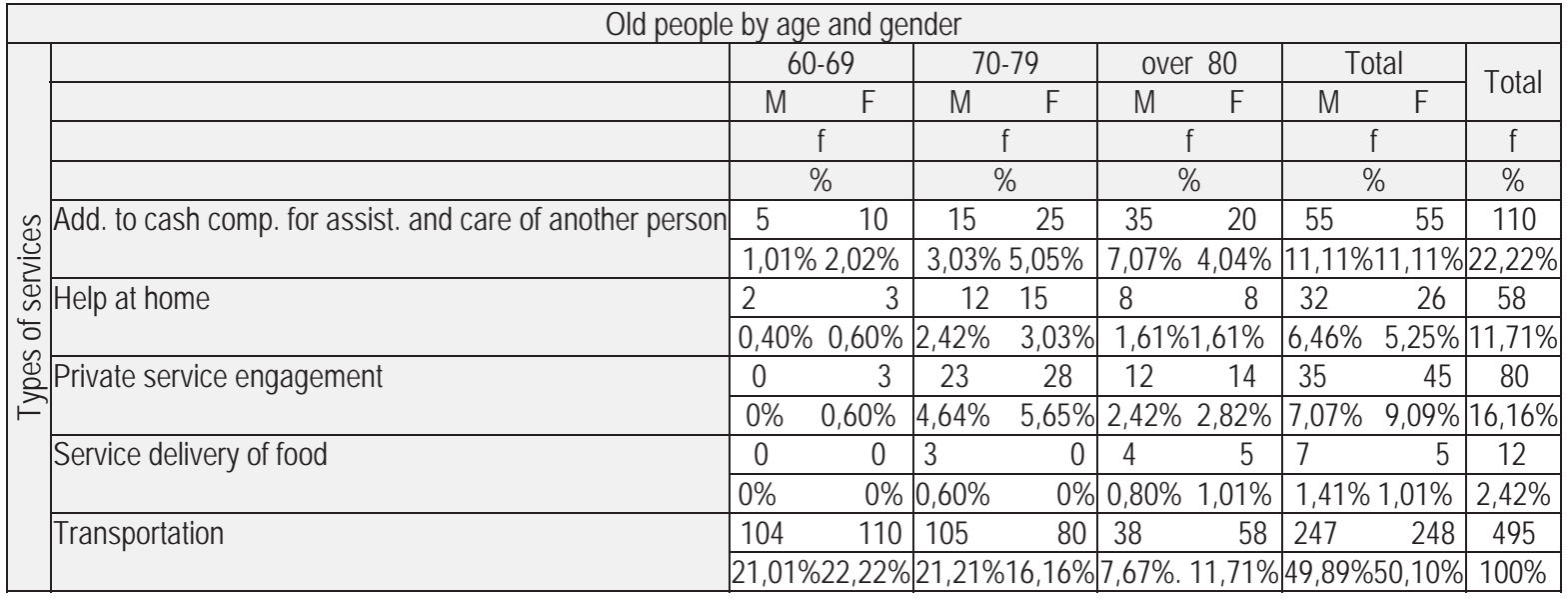

So far, in our country does not find useful and immediate, massive, reliable delivery of groceries and eating in the homes of the old people.

Although several supermarkets realized preparation and sale of ready meals (which is a positive step), we find that from one side it is still expensive for the low pensions of the old people and on the other side the facilities to purchase such products are distant from the place of living, and it makes it more difficult for the old people to access them.

Statistic indicators of the sample

\begin{tabular}{|c|c|c|c|}
\hline Symbols & $x^{2}$ & $\mathrm{C}$ & $\mathrm{N}$ \\
\hline Values & 10,128 & 0,248 & 165 \\
\hline
\end{tabular}

Statistic indicators of the theoretical values used for the investigation

\begin{tabular}{|c|c|c|c|}
\hline Symbols & Df & P\% & theoretical $\times^{2}$ \\
\hline \multirow{2}{*}{ Theoretical values } & 4 & 5 & 9,49 \\
\cline { 2 - 4 } & 4 & 1 & 13,28 \\
\hline
\end{tabular}

The $\times{ }^{2}$ size and intensity of the contingency show that there is a significant statistical relation between the old people and the types of services offered.

Within these stores are included the delivery services to home consumers, but the scarcity of food and the percentage required for delivering food to prevent the old people use this form of service. In terms of this presentation we can conclude that despite the high demand for these services are not enough realized in the life of the old people and require serious efforts from the government and NGOs for directly strengthening the old people in the realization of this form.

\section{Conclusion}

The findings on the status and challenges of the aging are based on the strive for the realization of progressive approaches, legislation, programs and strategies to improve the lives of the old people.

The main aim of this research is gaining knowledge and challenges in contemporary life of the old people, 
especially in terms of social care to create conditions, guidelines and bases for an organized approach.

In the context of all of this is made the central hypothesis of socioeconomic conditions of the modern living of the old people affect the policy of social care.

Testing this hypothesis is based on the analysis of the three main indicators in three main components and includes the basis of the conditions of the modern living of the old people.

The research confirms the importance of the basic hypothesis, respectively that the socioeconomic situation in living elderly affecting social care of the old people.

The highest percentage of the old people living in family groups, which confirms the theory that despite modern changes the old people are determined to live in the family.

It is very interesting that the research, in which the old people during the period of preparing for the aging imagine living alone (respectively with the partner), however when they enter the aging, the independent living (or loneliness) is least wanted form of quality living. Existential condition- in this term, the rsearch also showed that the situation of the old people is characterized by keeping modest life. A significant percentage (78. 8\%) of the old people cut overhead, preparing cooked meals two to three times a week, using cheap electricity, take care spending water other costs within their capabilities. The old people also cut into buying medicines, keeping in mind that this cost occupies a large part of the family budget.

The benefits of the city and intercity transport (bus, train) significantly facilitate the condition of life, but on the other hand using taxi services for emergences is rarely available, because it is expensive.

The services implemented in the home of the old person such as: helping the old person, private service engagement, service delivery of food, public health nursing, are services that facilitate the home living. However, the research also showed that they are present in relatively small percentage. Possible reasons for the difficulties in the implementation of services can be enumerated in the insufficient organization of social care, lack of information for direct work with the old people, the government and NGOs for accepting, because basically they treat with distrust and suspicion the unknown person in their home.

\section{Refferences}

Noelker, L. S. and Harel, Z. , 2001. 'Humanizing long-term care: forging a link between quality of care and quality of life' in Noelker, L. S. and Harel, Z. , (eds), 2001. Linking Quality of Long-Term Care and Quality of Life. Canada: Springer Publishing Company.

National Consumer Law Center. Helping Elderly Homeowners Victimized by Predatory Mortgage Loans. Consumer Concerns: Information for Advocates Representing Older Americans. 2006. Availablefromhttp: //www. nclc. org/images/pdf/older_ consumers/brochure_conversions_new/consumer_concerns/pdf/reg_size/cc_helping_elderly_homeowners_victimized_predatory _mtg. pdf (accessed 6 June 2010

Walker A. 2005, Understanding Quality of Life in Old Age, Published by McGraw - Hill Education, London,

Walker, A, 2004. 'The ESRC growing older research programme, 1999-2004', Ageing and Society, 24: 657-674.

World Economic and Social Survey (2007), Development in an Ageing World, Printed by The United Nations, New York, 2008

Wolf SL et al. (2003). Selected as the best paper in the 1990s: Reducing frailty and falls in older persons: An investigation of tai chi and computerized balance training. Journal of the American Geriatrics Society, 51 (12): 1794-1803.

World Health Organization (2002). Active ageing: A policy framework. Geneva.

www. stat. gov. mk

www. mtsp. gov. mk

www. jrf. org. uk/Knowledge/findings/socialcare

www. healthguidance. org/Living-With-Old-Age-And-Stress. html

www. nainfo. nbs. bg. ac. yu/dominantnepredstaveostarosti 